\title{
Memórias de escola
}

Vera Maria Tietzmann Silva*

\section{Resumo}

Este artigo pretende discutir como a escola e os professores são representados em textos autobiográficos em prosa e verso ou em narrativas que trabalham com personagens jovens em seus primeiros anos escolares.

Palavras-chave: autobiografias, infância, escolas e professores.

\section{School memories}

\section{Abstract}

This article sets out to discuss how schools and teachers are represented in autobiographical texts of poetry or prose or in narratives where the characters are young people in their early school years.

Keywords: autobiographies, childhood, schools and teachers.

A memória talvez seja um dos bens humanos mais valorizados, sobretudo hoje, quando vivemos um tempo de descartabilidade quase total. Qual âncora, a memória prende-nos ao passado, diz quem nós somos ao nos fornecer as referências que nos situam num tempo, numa família, numa cultura. Quem perde a memória perde com ela a própria identidade. À medida que os anos transcorrem, construímos nossa história pessoal acumulando um acervo de lembranças, e todo o processo educacional coloca-se a serviço desse treinamento da mente do aluno. Memorizar e lembrar são palavras de ordem.

* Professora Titular de Literatura Infantil e Juvenil da Faculdade de Letras da UFG. Mestre em Literatura Brasileira pela FL/UFG. 
No afã de treinar a memória e preservar as lembranças, muitas vezes deixamos de perceber que o esquecimento não é só negativo, ele pode também ser bom e necessário. Para nossa sanidade, a memória dispóe de um eficiente processo de autorregulação. De forma seletiva, registramos em nossos arquivos mentais apenas aquilo que nos parece relevante. Porém, os critérios que norteiam essa seleçáo não se situam no plano da consciência, não temos domínio sobre eles. De fato, eles muitas vezes nos surpreendem. Por que lembramos $\mathrm{x}$ e esquecemos $\mathrm{y}$, que na época nos parecia tão inesquecível?

Hoje o grande medo que nos assalta, à medida que a idade avança, é perder a memória. A doença mais temida já não é o câncer, é o mal de Alzheimer que, destruindo o cérebro, anula a pessoa. Com o mesmo afinco com que na juventude lutávamos para memorizar, na velhice lutamos para náo esquecer. Na criaçáo literária, a oposição lembrança x esquecimento encontra seu lugar nos relatos memorialistas. Ou nas ficçóes que tangenciam ou mimetizam esses relatos.

A literatura frequentemente situa suas tramas no terreno fértil da infância, seja criando ficçóes, seja recompondo memórias. Essa quadra da vida, principalmente se observada pelo distanciamento dado pelo tempo, muitas vezes adquire tons ideais de luminosidade e de harmonia que nem sempre correspondem à realidade vivida pela criança. Vista por um tal ângulo favorável, configura-se como a "idade de ouro", de contornos míticos, torna-se o Éden perdido que se deseja a todo custo recuperar.

Nas várias dezenas de livros autobiográficos em que escritores brasileiros relatam suas memórias da infância ou da adolescência, eles fazem isso ora através de um filtro positivo, nimbando suas lembranças de uma aura poética e emocionada, ora, ao contrário, lançam sombras e ressentimentos sobre esses anos que jamais gostariam de reviver. No domínio da poesia, Meus oito anos, de Casimiro de Abreu, é paradigmático da visão idílica da infância, enquanto os poemas de Cora Coralina sobre o cotidiano de Aninha, "daquela menina feia da rua da Lapa", são igualmente emblemáticos na representação da infância ressentida. Polarização semelhante pode ser observada na maior parte das obras memorialistas, que parecem refletir o tratamento dado à criança pela família, marcando-a com o signo do amor ou, ao contrário, da rejeição.

No panorama da infância mostrado pelas obras literárias nem sempre se inclui a escola. Menino de engenho (1932), de José Lins do Rego, e Indez (1991), de Bartolomeu Campos de Queirós, por exemplo, romances de tons 
fortemente autobiográficos, finalizam com a ida de seus protagonistas para o colégio, o primeiro para um internato, o segundo para a casa do avô na cidade. Deixar para trás o ambiente rural significa para eles abandonar a infância. Essa identificação entre o viver urbano e a disciplina escolar, representando ambas - cidade e escola - a perda da liberdade, pode ser também reconhecida nas obras infantis de Monteiro Lobato e nas de Mark Twain, de quem Lobato foi tradutor. Evidentemente, aqui já não se trata de relatos memorialistas como os mencionados, mas de narrativas ficcionais. Contudo, são ficções que trabalham com cenários e personagens semelhantes aos das autobiografias.

Nesses dois autores clássicos da literatura infanto-juvenil brasileira e norte-americana, a escola fica o tempo todo ostensivamente ausente. Pedrinho só vai ao sítio da avó no período de férias escolares, e as mençóes que faz à escola são sempre depreciativas. Em contrapartida, sua estada no sítio é marcada pelo aprendizado constante, que é feito na prática, no diálogo e nas leituras. Os personagens de Mark Twain, Huckleberry Finn e Tom Sawyer, parecem estar em férias permanentes, ainda que atuem como professores a seu modo, Tom prelecionando Huck, e este dando liçóes ao negro Jim. As explicaçóes que Huck dá a Jim sobre a diversidade das línguas, ou sobre os sucessivos casamentos do rei Henrique VIII são hilárias. Essas aulas informais, de didática e conteúdo bastante questionáveis, têm seu paralelo em Lobato, nas aulas que Emília dá ao anjinho trazido do céu, em Memórias da Emília, um livro que carnavaliza até mesmo o próprio gênero textual que assume a narrativa memorialista.

Entre os romances memorialistas que focalizam os primeiros anos do autor e sua passagem pela escola, Infância (1945), de Graciliano Ramos, é um bom exemplo. Num relato que se estende até os doze anos, o limiar da adolescência, o autor faz uma reconstituição autobiográfica, denunciando a rudeza das relaçóes familiares, em que o pai age mais como um padrasto carrasco (a palmatória sempre ao alcance da mão), e a mãe se fecha a qualquer demonstração de carinho. Nesse ambiente, o autor diz que se sentia um "menino troncho e esquisito", convencido, pelas grosserias do pai, de que era lento, ignorante, limitado, incapaz de aprender. É com essa baixa autoestima que ele ingressa na escola.

Narrativas ficcionais criadas como reminiscências escolares não são raras. Pela memória de seus protagonistas, Machado de Assis retratou duas cenas colegiais em "Conto de escola" e "Umas férias", textos canônicos de 
nossa literatura. A atmosfera sombria e rígida desses contos machadianos é a mesma que se observa nas lembranças de Graciliano, semelhante também à do romance O Ateneu (1888), de Raul Pompéia, que se equilibra na fronteira entre o vivido e o imaginado. Graciliano assim descreve sua sala de aula:

O lugar de estudo era isso. Os alunos se imobilizavam nos bancos: cinco horas de suplício, uma crucificação [...]. Não há prisão maior do que escola primária do interior. A imobilidade e a insensibilidade me aterraram. Abandonei os cadernos e auréolas, não deixei que as moscas me comessem. Assim, aos nove anos ainda não sabia ler. (RAMOS, 1993, p. 188)

Sua redenção como leitor não vem pela escola, mas por uma prima, que o incentivou a tentar ler sozinho, em silêncio, e pelo tabelião da pequena cidade interiorana, que lhe emprestou os livros de sua biblioteca particular e o orientou em suas leituras. Infância não é um livro otimista ou poético. As lembranças que o autor guarda de seu passado na família e na escola são amargas, a narrativa se faz, então, como libelo ou denúncia, sem resquícios de saudade. Fosse ficção, talvez Graciliano lhe desse o mesmo desfecho de O Ateneu, um incêndio que tudo consumisse, o prédio e suas recordaçóes.

Dois anos antes de Raul Pompéia lançar no mercado esse seu clássico, o italiano Edmundo de Amicis já havia publicado Coração (1886), um romance em forma de diário relatando a rotina de um menino no colégio e que, traduzido para o português por João Ribeiro, circulou amplamente no Brasil a partir de 1891. Capítulos dessa obra podiam ser encontrados em praticamente todas as Seletas e livros de leitura usados nas escolas brasileiras durante toda a primeira metade do século XX.

Contrastando com O Ateneu, Coração tem um clima lírico e nostálgico. Este último serviu de modelo para diversos escritores brasileiros que também retrataram o cotidiano escolar na ficção, com menor qualidade estética, ressalve-se. Podem citar-se Tales de Andrade e seu livro Saudade (1919), Viriato Correia e o infantil Cazuza (1938), ou Adelaide Carraro e as sucessivas (e lamentáveis) versōes de $O$ estudante.

Sem figurar no rol dos autores canônicos, uma escritora brasileira trouxe um olhar autobiográfico e feminino sobre o tema, num clima bem mais leve e arejado do que o de Pompéia e Amicis. Helen Morley, pseudônimo de Alice Dayrell Caldeira Brant, se valeu do mesmo formato de diário usado pelo autor italiano para relatar como era a vida de meninas no 
início do século XX, ampliando o leque de vivências para além dos muros da escola, estendendo-as para a vida na família e na comunidade, a pequena Diamantina do interior mineiro. Minha vida de menina (1942), que recebeu uma versáo para o cinema em 2004 (Vida de menina), é um livro agradável de ler, que dá uma visão original de um Brasil que saía da escravatura e da monarquia e entrava no século XX, um país bastante diferente do que hoje conhecemos. A motivação dessa escritora que estreava com mais de 60 anos era contar para as netas como se vivia na virada do século. Graciliano Ramos e Helen Morley são contemporâneos e escreveram seus livros na mesma década, mas as relaçóes familiares, o ambiente escolar e o tom geral que atravessa essas duas autobiografias são bem diferentes.

Nas memórias de Graciliano, a sua trajetória na conquista da leitura é o aspecto mais fortemente enfatizado. Esse foi o viés também escolhido para compor uma recente coletânea de reminiscências escolares. Organizado por Neide Medeiros Santos e Yolanda Limeira, o livro reúne depoimentos de 15 escritoras paraibanas sobre a experiência de leitura na infância e na adolescência, sob o título Memórias rendilhadas: vozes femininas (2006).

Quase uma década antes, Fanny Abramovich havia organizado Meu professor inesquecivel (1997), uma coletânea com depoimentos de escritores bem conhecidos, como Ana Maria Machado e Marina Colasanti. De todos os relatos, as vivências de Marina são as mais inusitadas, já que ela passou sua infância na Itália tomada pela guerra e não teve a rotina conhecida pela maioria das crianças. Ela conta, em seu depoimento intitulado "Hastes, bolinhas e sapatos apertados":

O percurso do meu ensino primário não foi exatamente regular. Tive muitas professoras, nem sempre terminei o ano com a mesma com quem o havia começado. Estudei em tantas cidades, em tantas mesas ou carteiras. Houve momentos em que atravessei campos cobertos de neve para ir à aula, em que deslizei ladeira abaixo sobre o gelo, sentada na pasta. Outros em que estudei tateando no bolso as conchas que havia catado um dia antes na praia. E os dias em que largava a aula no meio porque a sirene do alarme antiaéreo tocava e meu pai vinha me buscar de moto - esses, inconsciente como toda criança, eram os de que mais gostava. (COLASANTI apud ABRAMOVI$\mathrm{CH}, 1997$, p. 11)

Sua rotina era exatamente essa, não ter rotinas definidas, e ela comenta: "Inesquecível para mim é esse processo picotado e imprevisível, em que 
de alguma maneira tudo estava sempre recomeçando e sendo novo" (COLASANTI apud ABRAMOVICH, 1997, p. 12). Recentemente Marina lançou um livro de memórias da infância, Minha guerra alheia (2010), onde ela relata seus anos de África e Europa, anos de permanentes mudanças, de muitas casas, muitos professores, em que a rotina - se é que havia uma - era a de deixar quase tudo para trás e seguir adiante. De permanente, a família, em especial o irmão, seu companheiro de escola, de leituras e de brincadeiras. Permanente também o aprendizado, de vida e de leituras.

No domínio da literatura infantil, a irreverente Sylvia Orthof recupera lembranças da adolescência em Se a memória não me falha (1987) e em Livro aberto: confissóes de uma inventadeira de palco e escrita (1996), que, como o livro de Helen Morley, não se restringe ao colégio. Aliás, em Sylvia, esses livros lidam, cada um, com as lembranças de escola em escassos dois capítulos: "Heitor Villa-Lobos, Getúlio e a independência em festa" e "As aulas disso e daquilo", no primeiro; "Remendando lembranças" e "Qual o motivo da fuga do colégio?”, no segundo. Contudo, são nessas recordaçóes da escola, de suas aulas, de seus professores, do uniforme usado e das comemoraçôes cívicas que se encontram suas cenas mais interessantes e hilárias.

$\mathrm{Na}$ parte teórica com que inicia Memória e sociedade: lembranças de velhos, Eclea Bosi discorre sobre as concepçōes de Henri Bergson e Maurice Halbwachs acerca da memória. Ela explica:

O caráter livre, espontâneo, quase onírico da memória é, segundo Halbwachs, excepcional. Na maior parte das vezes, lembrar não é reviver, mas refazer, reconstruir, repensar, com imagens e idéias de hoje, as experiências do passado. A memória não é sonho, é trabalho. Se assim é, deve-se duvidar da sobrevivência do passado, "tal como foi", e que se daria no inconsciente de cada sujeito. A lembrança é uma imagem construída pelos materiais que estấo, agora, à nossa disposiçáo, no conjunto de representaçóes que povoam nossa consciência atual. (BOSI, 1994, p. 55)

Sabemos bem que a memória, além de seletiva, é bem pouco confiável. Assim é que Eclea Bosi prossegue em sua exposição, alertando-nos sobre como é escorregadio e capcioso o terreno por onde transitam as lembranças:

Por mais nítida que nos pareça a lembrança de um fato antigo, ela não é a mesma imagem que experimentamos na infância, porque nós náo somos os mesmos de então e porque nossa percepção alterou-se e, com ela, nossas 
idéias, nossos juízos de realidade e de valor. $\mathrm{O}$ simples fato de lembrar o passado, no presente, exclui a identidade entre as imagens de um e de outro, e propóe a sua diferença em termos de ponto de vista. (BOSI, 1994, p. 55)

Recentemente, o escritor mineiro Domingos Pellegrini publicou um livro intitulado Mestres da paixão: aprendendo com quem ama o que faz (2007), onde ele relembra os professores que teve em sua trajetória de aluno. No tema abordado - os professores inesquecíveis - ele se assemelha à coletânea organizada por Fanny Abramovich, com a diferença de que a dúzia de professores retratados nesse livro foram inesquecíveis para o mesmo autor, cada um deles por um motivo especial, cada um em um momento de sua vida.

Esse é, portanto, um livro de memórias escolares que tem a particularidade de centrar-se não no protagonista e seus colegas, mas nos professores que o autor teve em várias escolas, em diversos níveis de ensino, dando-lhe aulas das mais diferentes disciplinas. Para seu relato, o autor selecionou, numa linha cronológica, todos aqueles professores que, de algum modo, exerceram uma forte influência sobre ele, que contribuíram decisivamente para sua formação. Concluiu que todos eles eram vocacionados para o magistério, amavam o que faziam. Esse é justamente o segredo do bom profissional, qualquer que seja sua área de atuação, amar o que faz.

Quase todo mundo teve a graça de ter em sua vida a presença de um professor inesquecível, com a capacidade de "passar o vírus", de contagiar a turma, predispondo os alunos ao aprendizado, numa reação beirando a química - algo que, nem mesmo com toda a moderna tecnologia, máquina alguma consegue fazer. Mais do que isso, professores cujo comportamento deu a seus alunos aulas de ética, de honestidade, de justiça e de solidariedade. Também eu os tive e pude falar sobre eles em Baú da memória: crônicas do colégio (2010), um pequeno volume de lembranças ginasiais, vividas no final da década de 1950. Nesse livro, avulta sobre os demais elementos narrativos, quase como protagonista, o Colégio São José, uma instituição centenária, onde estudei por quase dez anos e onde depois fui também professora.

Quem escreve memórias? Para que se escrevem memórias? E por que lemos as memórias dos outros? Essas são perguntas que podem ocorrer a quem se depara numa livraria com um livro de narrativa autobiográfica. Que interesse pode haver nos fatos que marcaram a vida dos outros, de pessoas que o leitor nunca viu, que viveram num tempo que não é o seu, que tiveram problemas que não lhe dizem respeito? 
Quem escreve memórias, no fundo, sempre é movido pelo desejo de não ser esquecido, de permanecer, de ultrapassar as limitações humanas. $\mathrm{O}$ poeta romano Horácio dizia que as palavras são mais duradouras do que o bronze, e ele tinha razão. É pela palavra que os memorialistas buscam perpetuar-se, nem que seja apenas dentro do círculo restrito de sua própria família.

Freud afirmava que, no seu íntimo, todos os homens acreditam ser imortais. Essa obscura convicção justifica o dito popular de que todas as pessoas devem "plantar uma árvore, ter um filho e escrever um livro". São nossas alternativas de perenidade.

E quanto ao leitor? Quem lê memórias é movido por uma sensação de compartilhamento, ou de comunhão, com o autor. Lendo um texto memorialista, o leitor vivencia a emoçâo alheia, sente-a como sua. É a isso que o teórico Maurice Halbwachs (1990, p. 26) chama de "memória coletiva":

Nossas lembranças permanecem coletivas, e elas nos são lembradas pelos outros, mesmo que se trate de acontecimentos nos quais só nós estivemos envolvidos, e com objetos que só nós vimos. É porque, em realidade, nunca estamos sós. Não é necessário que outros homens estejam lá, que se distingam materialmente de nós: porque temos sempre conosco e em nós uma quantidade de pessoas que não se confundem.

Assim, quando alguém registra num livro de memórias suas próprias lembranças, por mais pessoais que essas recordaçóes sejam, elas ultrapassam as fronteiras do individual. A memória pessoal é toda impregnada pelo coletivo. Por um lado, isso permite que ela seja compartilhada pelo outro, que nela se reconhece. Por outro, ela funciona como registro de um tempo, de uma geração ou de um povo. Minha vida de menina, por exemplo, vai muito além das parcas experiências de uma menina interiorana, que preferiu esconder-se sob um pseudônimo. É o retrato de um tempo marcado por grandes mudanças políticas e sociais no Brasil, é um retalho, pequeno embora, da história deste país.

A memória pessoal converte-se em memória coletiva quando reconstrói a fisionomia de uma dada época, de uma cultura ou de um país. $\mathrm{Ou}$ seja, quando à memória individual soma-se a memória social, como se vê no livro de Helen Morley. Numa perspectiva metonímica, poderíamos afirmar que a memória de um é sempre, em alguma medida, a memória de todos. 
Árvores, filhos, livros. Essas imagens trazem à mente o transcurso do tempo, que se repete e se renova nas sementes que germinam e tornam a gerar novas árvores, nos filhos que crescem e geram outros filhos, nos livros que, lidos, inspiram outros livros a outros leitores. A natureza, a família e a cultura são heranças que recebemos de graça e que temos o dever de preservar como legado aos que vierem depois de nós. Por meio desses legados, acessíveis de algum modo a quase todos nós, podemos nos manter nessa corrente que dá sentido à nossa vida, que nos faz participantes do poder divino de criar e, pela criação, de nos eternizarmos.

\section{Referências}

ABRAMOVICH, F. (Org.). Meu professor inesquecivel. São Paulo: Editora Gente, 1997.

AMICIS, E. de. Coração: diário de um menino. Tradução de João Ribeiro. 53. ed. Rio de Janeiro: Francisco Alves, 1968.

BOSI, E. Memória e sociedade: lembranças de velhos. 4. ed. São Paulo: Companhia das Letras, 1994.

COLASANTI, M. Minha guerra alheia. Rio de Janeiro: Record, 2010.

HALBWACHS, M. A memória coletiva. Tradução de Laurent Leon Schaffter. São Paulo: Vértice, 1990.

LIMEIRA, Y.; SANTOS, N. M. (Orgs.). Memórias rendilhadas: vozes femininas. João Pessoa: Editora Universitária/UFPB, 2006.

LOBATO, J. B. M. Memórias da Emília. 42. ed. São Paulo: Brasiliense, 1994.

MACHADO, A. M. Esta força estranha: trajetória de uma autora. São Paulo: Atual, 1996.

MORLEY, H. Minha vida de menina. São Paulo: Companhia das Letras, [1942] 1999.

ORTHOF, S. Se a memória não me falha. Rio de Janeiro: Nova Fronteira, 1987. 
438 Polyphonía, v. 21/2, jul./dez. 2010

Livro aberto: confissóes de uma inventadeira de palco e escrita. São Paulo: Atual, 1996.

PELLEGRINI, D. Mestres da paixão: aprendendo com quem ama o que faz. São Paulo: Moderna, 2007.

POMPÉIA, R. O Ateneu. Cotia, SP: Ateliê, 1999.

RAMOS, G. Infância. Rio de Janeiro: Record, [1945] 1993.

SILVA, V. M. T. Baú da memória: crônicas do colégio. Goiânia: Cânone, 2010.

Recebido em: 16 mai. 2011

Aceito em: 23 ago. 2011 